\title{
Coarse-Grained Geological Porous Media Structure Modeling Using Heuristic Algorithm and Evaluation of Porosity, Hydraulic Conductivity, and Pressure Drop with Experimental Results
}

Javad Bezaatpour ( $\nabla$ j_bezaatpour@sut.ac.ir)

Sahand University of Technology https://orcid.org/0000-0002-6818-207X

Esmaeil Fatehifar

Sahand University of Technology https://orcid.org/0000-0003-3800-2442

Ali Rasoulzadeh

University of Mohaghegh Ardabili

\section{Research Article}

Keywords: SWRC, Porous Media, Random Close Packing, Heuristic Algorithm, Pressure Drop, ASTM D2434-68

Posted Date: April 27th, 2021

DOl: https://doi.org/10.21203/rs.3.rs-357631/v1

License: (c) (1) This work is licensed under a Creative Commons Attribution 4.0 International License. Read Full License

Version of Record: A version of this preprint was published at Environmental Earth Sciences on July 19th, 2021. See the published version at https://doi.org/10.1007/s12665-021-09699-z. 


\title{
Coarse-Grained Geological Porous Media Structure Modeling Using Heuristic Algorithm and Evaluation of Porosity, Hydraulic Conductivity, and Pressure Drop with Experimental Results
}

\author{
Javad. Bezaatpour. ${ }^{a}$, Esmaeil. Fatehifar. ${ }^{* a}$, Ali. Rasoulzadeh. ${ }^{\text {b }}$ \\ a Productivity and Sustainable Development Research Center, Faculty of Chemical Engineering, Sahand \\ University of Technology, P.O. Box: 513551996, Sahand New Town, Tabriz, Iran \\ ${ }^{\mathrm{b}}$ Water Engineering Department, Faculty of Agriculture and Natural Resources, Member of Water Management \\ Research Center, University of Mohaghegh Ardabili, P.O. Box: 179, Ardabil, Iran
}

\section{Abstract}

Knowledge of porous media structure is an essential part of the hydrodynamic investigation of fluid flow in porous media. To study soil behavior (as a granular porous media) and water and contaminant movement in the vadose zone, appropriate estimation of soil water retention curve (SWRC) and soil hydraulic conductivity curve (SHCC) has a pivotal role and is one of the most challenging topics for researchers and engineers in soil and water science. The SWCR can be approximated using an accurate particle size distribution (PSD) function. In this study by applying random close packing ( $\mathrm{RCP})$ method as an encouraging method for predicting and studying particle configuration, an optimal particle size distribution is developed for coarsegrained soils $(0.025 \mathrm{~mm}<\mathrm{PSD}<3.35 \mathrm{~mm})$. The mentioned RCP is generated using heuristic algorithm with merging applicable equations of soil science. For porous media modeling, MATLAB software is used and the predicted results by the optimal model for the parameters of porosity, pressure drop, and saturated hydraulic conductivity are compared with laboratory

\footnotetext{
${ }^{*}$ Corresponding author. Telefax: +984133459141

E-mail Address: fatehifar@sut.ac.ir (E. Fatehifar)
} 
measurements. Experimental design is conducted by MINITAB and predicted coarse-grained

soils structure by the model is compared with 4 sifted soils. The results of the sensitivity analysis showed that the porosity obtained from the model is strongly sensitive to the resolution factor and should be chosen with a sufficiently large amount (higher than 250). Results showed good consistency (up to $95 \%$ ) between predicted porosity and only $10 \%$ difference in pressure drop and permeability with observed measurements.

Keywords: SWRC, Porous Media, Random Close Packing, Heuristic Algorithm, Pressure Drop, ASTM D2434-68

\section{Introduction}

Soil water retention curve (SWRC) is a powerful and instructive tool to prognosticate soil behavior and water and contaminants movement in the vadose zone. (Tong et al. 2012). SWRC describes the soil matric suction (h) as a function of volumetric soil moisture $(\theta)$ or vice versa and along with soil hydraulic conductivity curve (SHCC) is utilized to estimate soil hydraulic properties (Braddock et al. 2001). There are several empirical and theoretical methods for predicting SWRC in literature. The ASTM D6836-16 has been developed to laboratory measure SWRC consisting five standard methods (A to E) at various suction ranges (Leong 2019). Another conventional laboratory method for estimating SWRC is to use the particle size distribution (PSD) curve and volume-mass properties (Wen et al. 2020). One of the theoretical methods is to apply the pore size distribution function (PoSD) and develop soil characteristic curve based on the soil pores network (Chen et al. 2019; Fredlund et al. 1994). It should be noted that unlike PSD, PoSD is affected by climatic conditions (temperature, soil moisture content, number of rainy or rainless months) and even could change with soil shrinkage (Wen et al. 2021). Of course, some physical-based conceptual models have been propounded to predict SWRC. In these models, by using an appropriate PSD function and then conversion to 
In most of cases, particles and pores are assumed as solid spheres and void cylinders, respectively. However, the fundamental weakness raised about conceptual models is that they do not consider spheres in the aggregate or packed form in a specified volume. The present study focuses on this important gap, so that by eliminating it an optimal function for PSD are provided. In recent years porous media structure prediction by computer modeling has become one of the researcher's favorite topics. Random close packing and pore network modeling (PNM) methods are used in many types of research and engineering sciences such as studying composite structures (Wu et al. 2010), distribution and loading of catalyst beds in chemical reactors (Dorai et al. 2012), study of different polymers (Ch et al. 2013), hydrocarbon-bearing reservoir rock (Al-Dhahli et al. 2013), microstructure and powder-based structures material (Benabbou et al. 2010; Zhou et al. 2009), packing cartons problems (Wu et al. 2017), etc. In mathematics, the problem of packing particles in a limited space is a subset of optimization problems. In RCP method, solid particles are assumed as spherical, cylindrical, and cubic or pyramid (Li et al.2010). Depending on the complexity and structure of considered media, using a combination of these figures is suggested. RCP method investigates the packing and relation of soild particles in scale under consideration. On the other hand, porosity, void spaces and channeles' connections are subject of PNM method. In this method (for instance in 2D state), the channels and throats between particles are considered as circles and rectangles, respectively (Xiong et al. 2016). Euler approach is the prominently used approach in RCP and Lagrange approach is so in PNM method. Therefore, the results are not so different from each other. Particles could be used in the same size or with a size distribution (Baranau and Tallarek 2014; Daneyko et al. 2011; Santiso and Müller 2002). Packed media with spherical particles then compared on their porosity and coordination number. Particle density defined as total solid 
of a specific particle (Anikeenko et al. 2008; Farr and Groot 2009). Porosity can be calculated from particle density. In RCP method, mechanical contraction, Monte Carlo, particle drop and roll, spherical growth, and Lubachevsky-Stillinger (L-S) algorithm are among important rudimentary algorithms (basic algorithms) for the construction of porous media (Hitti and Bernacki 2013; Kansal et al. 2002; Kyrylyuk et al. 2009; Tobochnik and Chapin 1988). Hybrid or heuristic methods commonly are a combination of the above algorithms or algorithms with improved and coupled equations. For the mechanical contraction (sedimentation) algorithm introduced by Williams and Phillips (2003), first, all particles are generated in a finite space using a random distribution function. In order to minimize the space occupied by the particles and achieve the desired porosity, the particles' z-coordinate is reduced as much as possible based on their initial position. According to the definition of the non-overlap constraint for solid particles, each particle is sedimented vertically until it reaches the bed of stable stationary particles. The most important drawback of this method is the creation of unconventional spaces. This algorithm is strongly dependent on the initial position of the generated particles in the studied volume. Although by changing the diameter of the particles and their initial position, this problem can be partially eliminated, but in any case, achieving the optimal arrangement is one of the main problems of this method. In the spherical growth algorithm, after producing the first particle as the central nucleus (core) of the set, considering the minimum particles distance and non-overlapping conditions, the first layer of particles is created in the vicinity of the desired particle. In this method, the growth of the layers surrounding the central core is circular (for 2D assumption). By increasing the circumfluent boundary of particles, the computation time increases significantly. Because the newly loaded particle sweeps the entire boundary of the set to achieve the optimal position (minimum distance from the central core) (Bargmann et al. 2018). He et al. (1999) proposed the Monte Carlo method for producing particles with different sizes in an arbitrary finite volume. According to the Monte Carlo 
97 algorithm, all particles are produced in completely initial random coordinates and smaller than their actual size. Then, by concerning the non-overlapping and volume interference constraints, the particles' volume is increased to achieve a dense arrangement with the desired density and porosity. Like the mechanical contraction method, this method is also affected by the initial position of the generated particles. However, in this method, by replication of the results (for example, up to 10,000 replication), the mentioned problem is eliminated and by averaging the results, the best arrangement and porosity is evaluated. For the drop and roll algorithm, developed by Visscher and Bolsterli (1972), unlike the Monte Carlo and the mechanical contraction methods in which all particles are generated simultaneously, the creation and evaluation of the stable position of the particles are investigated one by one. This method is more complex than previous methods and its calculation time is very long, But the results are more precise. It is worth noting that the RCP method is the starting point for research on porous media. Indeed, after modeling and generation the structure of the porous media, various aspects such as the fluid flow, the rate of thermal resistance (or shape alteration), and the compressibility of the porous media are investigated.

As mentioned before, the main objective of this study is to propose modified PSD and an upgraded mathematic model to predict coarse-grained soils structure as a typical granular porous media. The heuristic algorithm which is presented for the first time in this study is the combination of "spherical growth" and "dropping and rolling" by implementation of modified functions in the matrix domain.

\section{Modeling and System Parameters}

In order to predict the soil structure (sifted soil) RCP method is implemented by MATLAB coding. The heuristic algorithm applied in this study is the combination of "spherical growth" and "dropping and rolling" with some modified equations. Soil particles are assumed as 
spherical solid particles. In this model objective function is a random distribution of spherical particles in a finite cubic volume. Whereas soil media is continuum and continuum media modeling is difficult and more time-consuming, so in the first step, the mentioned cube (called finite volume) meshed up as depicted in Fig. 1. Discretizing and meshing precision is included by defining the resolution factor (RF). As shown in Fig. 1, just a set of specified nodes are utilized instead of the whole points of continuum media. These nodes represent their surrounding media. Obviously, more node leads to more precision which takes more run time and RAM capacity. Node numbers depend on the smallest particle size because correct packing and occupation of each node by particles (spheres) must be guaranteed. Two functions to satisfy these conditions are defined as Eq. (1) and Eq. (2).

$$
\begin{aligned}
& R F=f\left(t_{c a l}, d_{i}, n_{i}, L_{c}\right) \\
& \varepsilon=g\left(R F, d_{i}, n_{i}\right)
\end{aligned}
$$

In the above equations, tcal $_{\text {cal }}$ points to calculation time, $\mathrm{d}_{\mathrm{i}}$ refers to particles (spheres) diameter, $\mathrm{n}_{\mathrm{i}}$ is the number of each particle, $\mathrm{L}_{\mathrm{c}}$ is cube edge size, and $\varepsilon$ is the estimated porosity. In Fig. 1, grid spacing (called mesh-grid) is obtained by Eq. 3 as follows:

$$
\mathrm{L}_{\mathrm{m}}=\frac{\mathrm{L}_{\mathrm{c}}}{\mathrm{RF}}
$$

In which $\mathrm{L}_{\mathrm{m}}$ notes two nodes distance and $\mathrm{L}_{\mathrm{c}}$ is cube edge size. Nodes coordination $\left(\mathrm{x}_{\mathrm{i}}, \mathrm{y}_{\mathrm{i}}, \mathrm{z}_{\mathrm{i}}\right)$ is assumed as a center of spheres. It should be noted that in matrix space if the center of enough large sphere is allocated to an arbitrary grid (sphere whose radius is bigger than two neighbor node distance), necessarily some of neighboring grids would be enclosed too. Therefore, necessarily each node is not at the center of a sphere. But surely every sphere is placed at the center in a randomly selected node (Fig. 2-a). The next step is to define of a random function for the completely random placing of particles. In each computational step, a group of nodes occupied by each sphere with an optional radius which produced by the rand function in 

random functions in 3-dimensional spaces. Many studies show the best approximation could be obtained using Weibull distribution for size distribution of soils (Esmaeelnejad et al. 2016; Rhodes 2008). Therefore, Weibull and normal distribution functions are employed in MATLAB to construct spheres with random diameters. Neglecting these nodes for the next placement is obligatory since counterpart soil particles couldn't overlap each other (Fig. 2-b). It's also an important point to reduce computational time. As it's shown in Fig. 2-b, in 2D space and for a general $(i, j)$ node chosen as circle center point, neighboring nodes also placed inside of the circle so won't be considered again. This important condition is implemented by defining matrixes with zero and one arrays. The matrixes that include number one array represent nodes that have not yet been occupied by the particle. For the next ball (with specified random radius) placement, the nearest node with minimum $\mathbf{z}$ to the last sphere would be selected according to Fig. 2-a and Fig. 2-c. Indeed, to increase the computational speed, the probability function is defined for the remaining nodes. In order to place the next sphere, the distance of all remaining nodes from the center of the previous sphere is calculated in the matrix domain. A node which is selected for the center of the next sphere must fulfill two constraints. The minimum distance from the center of the previous sphere and its minimum $\mathrm{Zi}$ coordinate. The probability matrix is calculated for all remaining nodes and the node with the largest array (maximum probability) is selected. Obviously, in this case, there will be nodes with equal probability density (Fig. 2b). After assigning the node as the center of the sphere (with a random radius), the nonoverlapping condition is tested by calculating the Euclidean distance of the node from the node allocated to the central core. If the above condition would not true, the node is stored in a matrix called NAN and removed from the calculation cycle, and the next node is chosen with the maximum probability. This cycle is continued until the particle loaded correctly and the next 
combination of "spherical growth" and "drop and rolling" algorithms by implementation in matrix space. To apply this idea, the cubic volume which contains particles is divided into $\boldsymbol{m}$ sublayers. Then by using conditional statements to constrain model to necessarily fill the first layer with spheres and do not proceed to the next layer until the previous layer (or nodes) completely filled. After placement of each sphere, this sphere acts as a central (core) sphere for the next adjacent spheres. The 2-dimensional case of this process is represented in Fig. 2-d. Sphere number represents its placing order. Flowchart of all calculations and particles placement in confined volume is shown in Table 1.

Our main research goal is to investigate contaminant dispersion in soil. In the first step, we need to have a good estimate of SWRC and SHCC. As mentioned before, one way to predict SWRC is to use the accurate PSD function. In the present study by applying heuristic algorithm the structure and particle configuration of coarse-grained soils are investigated. Besides, properties such as porosity (or saturated volumetric humidity), saturated hydraulic conductivity and pressure drop are evaluated. These parameters are strongly influenced by soil texture and structure. Soil texture indicates the percentage of sand, silt, and clay particles and is an important criterion of soil PSD. However, the structure of the soil explains the configuration and arrangement of these particles. Therefore, we want to know this method of RCP to generate porous media which uses spheres, how closely resembles real media.

\section{Material and Equipment}

For preparing laboratory coarse-grained soils, a specified amount of soil is collected and sorted by different grain sizes using standard laboratory sieves which are used for gradation test as it's shown in Table 2.

In order to ensure uniform PSD for each mesh, screening with a mechanical shaker is repeated three times. A plastic hammer was used during meshing to eliminate dust. Four sets with 
specific mesh sizes are shown in Fig. 3. Four types of coarse-grained soils are provided by mixing all of the above four particle size groups with mass weight mixing ratios as shown in Table 3. These mixing ratios are also used for modeling coarse-grained soils in MATLAB. For each size classification, Weibull and normal distribution functions are employed. Indeed, to generate spheres with random diameter, four Weibull and normal distribution functions are applied.

For a random variable $\mathrm{X}$ (diameter of spheres) that takes positive and continuous values, the Weibull probability density function is presented by Eq. (4) as follows:

$$
f(x ; \lambda, k)= \begin{cases}\frac{k}{\lambda}\left(\frac{x}{\lambda}\right)^{k-1} & e^{-(x / \lambda)^{k-1}} \\ 0 & x \geq 0 \\ 0 & x<0\end{cases}
$$

Where $\mathrm{k}$ and $\lambda$ refer to shape and scale parameters, respectively.

\subsection{Porosity Measurement}

In order to porosity measurement of the mentioned laboratory coarse-grained soils, standard stainless steel cylinders $(100.00 \mathrm{ml})$ were filled with them and saturated with water. Cylinders' weight was measured precisely before and after filling with soil and then water. Then the samples were placed in an oven at $105^{\circ} \mathrm{C}$ for 24 hours to ensure that all its moisture content evaporated. Samples' weight was measured again and porosity was calculated by its difference to previous measurements. For each soil, this experiment was repeated 3 times to ensure the accuracy of the results. The cylinders containing sifted soils are shown in Fig. 4.

\subsection{Pressure Drop and Permeability}

One important parameter that affects fluid flow in porous media, is pressure drop due to porous media resistance to flow through pores. Pressure drop increases by effective porosity reduction. 
212 A modified equation based on Kozeny-Carmen equation (Rhodes 2008) is utilized to

213 investigate the pressure drop in the model. For a porous media with identical spherical grain,

214 pressure drop could be expressed as Eq. (5):

$$
\frac{\Delta \mathrm{P}}{\mathrm{L}}=\frac{180 \mu}{\varphi_{\mathrm{S}}^{2} \mathrm{D}_{\mathrm{P}}^{2}} \frac{(1-\varepsilon)^{2}}{\varepsilon^{3}} \mathrm{v}_{\mathrm{S}}
$$

215 In which $\Delta \mathrm{P}$ is pressure drop, $\mathrm{L}$ is length, $\mu$ is dynamic viscosity, $\mathrm{v}_{\mathrm{s}}$ is superficial velocity, $\varepsilon$ is

216 porosity, $\varphi_{s}$ is sphericity (which is equal one for a perfect sphere) and $D_{p}$ is equivalent grain

217 diameter. Using Darcy law and rearranging Kozeny-Carman equation, the permeability of a

218 porous media with identical sphere grain could be written as below:

$$
\begin{aligned}
& \mathrm{v}_{\mathrm{s}}=\frac{\mathrm{k}}{\mu} \frac{\Delta \mathrm{P}}{\mathrm{L}} \\
& \mathrm{k}=\frac{\varphi_{\mathrm{s}}^{2} \mathrm{D}_{\mathrm{P}}^{2}}{180} \frac{\varepsilon^{3}}{(1-\varepsilon)^{2}}
\end{aligned}
$$

219 Permeability and saturated hydraulic conductivity relation could be expressed by Eq. (8):

$$
\mathrm{k}=K_{s} \frac{\mu}{\rho \mathrm{g}}
$$

220 In which $\mathrm{k}$ is the permeability of porous media in $\mathrm{m}^{2}, \mathrm{~K}_{\mathrm{s}}$ is hydraulic conductivity in $\mathrm{m} \cdot \mathrm{s}^{-1}, \mu$

221 is dynamic viscosity in $\mathrm{kg} \cdot \mathrm{m}^{-1} \cdot \mathrm{s}^{-1}, \rho$ is fluid density in $\mathrm{kg} \cdot \mathrm{m}^{-3}$ and $\mathrm{g}$ is gravity acceleration in $222 \mathrm{~m} \cdot \mathrm{s}^{-2}$ (Loll et al. 1999). To precisely estimate the saturated hydraulic conductivity of groups of 223 jammed sphere grains with different diameters, Irani and Callis (Irani, C.F., Callis 1963) 224 equation is used (Eq. 9a-9d). This applicable equation represents the equivalent mean diameter 225 for a group of soil particles with different sizes.

$$
\begin{aligned}
& \sigma_{g}=e^{b} \\
& d_{g}=e^{a}
\end{aligned}
$$


$a=0.01 \sum_{i=1}^{n} f_{i} \operatorname{Ln} M_{i}$

$b=0.01 \sum_{i=1}^{n} f_{i} L^{2} M_{i}-a^{2}$

226 In which $d_{g}$ is the mean diameter of grains, $\sigma_{g}$ is the variance of grain size distribution, $n$ is the

227 number of different grain size groups, and $\mathrm{f}_{\mathrm{i}}$ is the mass percent of grains which has diameter equal or less than $\mathrm{M}_{\mathrm{i}}$ in each group. Following the recommendation for application of geometric mean diameter to sieved sediments, $\mathrm{M}_{\mathrm{i}}$ is taken as the arithmetic mean of two consecutive particle size limits (Shirazi and Boersma 1984). Therefore, by using the mentioned equation and also using Weibull and normal distribution functions to generate spheres with different diameters, the mean diameter is calculated for four types of sifted soils.

\subsection{Laboratory investigation of pressure drop}

ASTM D 2434-68 is used for measuring pressure drop and saturated hydraulic conductivity in soil porous media. This standard is used to measure the pressure drop and hydraulic conductivity of disturbed granular soils in saturated conditions. Setup of the experiment is shown in Fig. 5. Sifted soils from previous steps $(65 \mathrm{~kg})$, are used for experiments.

\subsection{Experimental Design Method}

By applying "Minitab" software and general full factorial design method, the order of experiments is completely randomized. Each experiment is repeated three times to assure the validity and accuracy of the results. Total number of 72 experiments are carried out. 6 treatment of 49, 59, 69, 79, 89, and $95 \mathrm{~cm}$ water head (constant water head) are used for four soil types. Due to using sifted soil particle which has specific grading, it is expected that pressure drop would be the same for the equal depth of column as soil prepared homogenously. 


\section{Modeling and Laboratory Results}

246 The model result for type 1 soil structure is delineated as an example in Fig. 6. Also, the

247 structure of the coarse-grained soil for the particle size distribution of 25 microns to 3350 microns is shown in Fig. 7. Comparison of the results between normal and Weibull distribution functions showed that the Weibull distribution function has much better results in estimating soil porosity. In the next step, to reduce the difference between the estimated and empirical porosity, the skewness and elongation coefficients of the Weibull distribution function (in the terms of shape and scale parameters) were inclined to negative values. As a result, the use of the modified Weibull distribution function led to the development of an optimal RCP model for predicting porosity. According to the symmetric shape of the normal distribution function (around the mean value of each desired grain size range), its skewness coefficient is zero and its default elongation coefficient is 3 . Comparison of the siefted soils porosity and the corresponding optimal RCP model showed that the average relative error between the two porosities is less than $4 \%$. While for the normal distribution function, the predicted porosity showed larger values and the relative error percentage was up to $8.9 \%$. The predicted values of porosity by mathematic optimal model and experimental data for four types of soils is presented in Fig. 8. The most important parameters in determining the porosity of the porous medium were replication, resolution factor, and particle size distribution function. Modeling of particles configuration carried out in two modes which were the least and most effective magnitude. While the rest of the parameters were assumed to be constant (see Table 4). The results of the sensitivity analysis showed that the porosity obtained from the model is strongly sensitive to resolution factor and should be chosen with sufficiently large amounts. The results are represented in Fig. 9. By using a modified distribution function for sphere diameter and choosing a high-Resolution factor $(\mathrm{RF}>250)$, the relative error of porosity reduced to less than $3 \%$. By normal distribution function and $50<\mathrm{RF}<100$, relative error up to $10 \%$ obtained. 
270 Resolution factor is a criterion of discretization accuracy and the number of nodes in the cube.

271 For example, for a cube with a length of $1 \mathrm{~cm}$ and $\mathrm{RF}=200$, there would be $8 \times 10^{6}$ nodes. In this

272 case, it's obvious that run time increases exponentially too (over 10 hours for $R F=200$ and a

273 week for $\mathrm{RF}=300$ ). By approaching higher $\mathrm{RF}$ values and using the appropriate conditional

274 clause in Weibull distribution function, we could obtain spheres which closely approximate the

275 real condition and build an optimum model with a more precise answer, but it needs higher

276 computational power and run time. The predicted results for pressure drop reveals that Weibull

277 distribution function gets a more accurate result than normal distribution function (Fig. 10). As

278 porosity value obtained by models overestimates real values, accordingly calculated pressure

279 drops are less than measured values. This could be the result of Irani and Callis equation error

280 in estimating mean diameter and Boersma's (Shirazi and Boersma 1984) proposed relation to

281 calculate the arithmetic mean particle diameters for each grain classification. The average

282 difference between actual pressure drop and estimated by the RCP model (using the normal

283 distribution function) was $23.3 \%$. While by applying the modified Weibull distribution

284 function, this difference was reduced to less than $10 \%$. As is expected, almost in all experiments

285 such result for $\Delta \mathrm{P} / \mathrm{L}$ was observed in manometers which is shown in Fig. 11. Saturated

286 hydraulic conductivity of sifted soils (in the range of sandy soils) was measured using ASTM

287 D 2432-68 and it was compared with model estimates. As an example, Estimated saturated

288 hydraulic conductivity and measured values for soils type one and two are shown in Fig. 12.

289 As previously explained, the modified Weibull distribution function is used to reduce the

290 pressure drop difference to less than 10\%. Subsequently, given Eqs. (5) and (7), saturated hydraulic conductivity values are predicted up to $10 \%$ larger than the actual values. 
293 In this research innovative algorithm is employed to generate sandy soil porous media which 294 is the combination of "dropping and rolling" and "spherical growth" algorithms. The main 295 advantage of this algorithm is the utilization of continuous media discretization method and transforming to matrix space which could successfully model porous media. Also, by using

297

\section{Abbreviation}

\section{Future Study} applied equations in soil science, and modified Weibull distribution function, an optimal RCP model was developed to predict the parameters of porosity, pressure drop, and saturated hydraulic conductivity. Comparison of the results of the optimal model and laboratory investigations reveals that the difference between the predicted and measured porosity is less than $4 \%$. A difference of $10 \%$ is also observed for the parameters of pressure drop and saturated hydraulic conductivity. One of the unique characteristics of this model is building completely organized and structured porous media which happens for equal and monodispersed spheres in the range of $30<\mathrm{RF}<70$ (represented in Fig. 13).

Providing a suitable model to predict SWRC has always been a favorite of researchers. By applying a proper PSD and also ratios of fine sand/silty clay mixtures to their maximum densities, we can propose a conceptual model to prognosticate SWRC with acceptable accuracy. Indeed, after finding the PSD, using the suggested equations, we will try to obtain the corresponding PoSD function, and finally, SWRC will be predicted based on PoSD.

RCP: Random Close Packing 
317 PSD: Particle Size Distribution

318 PoSD: Pore Size Distribution

\section{Appendix. Nomenclature}

\begin{tabular}{|c|c|}
\hline $\mathrm{d}$ & diameter (m) \\
\hline $\mathrm{D}_{\mathrm{p}}$ & equivalent grain diameter (m) \\
\hline f & mass percent \\
\hline g & gravity acceleration $\left(\mathrm{m} \cdot \mathrm{s}^{-2}\right)$ \\
\hline $\mathrm{h}$ & matric suction $(\mathrm{m})$ \\
\hline $\mathrm{k}$ & permeability of porous media $\left(\mathrm{m}^{2}\right)$ \\
\hline $\mathrm{K}_{\mathrm{s}}$ & saturated hydraulic conductivity $\left(\mathrm{m} . \mathrm{s}^{-1}\right)$ \\
\hline $\mathrm{L}$ & length (m) \\
\hline $\mathrm{L}_{\mathrm{c}}$ & cube edge length (m) \\
\hline $\mathrm{L}_{\mathrm{m}}$ & mesh grid (m) \\
\hline $\mathrm{m}$ & number of sublayers \\
\hline $\mathrm{n}$ & number of particles \\
\hline$n_{i}$ & number of particles in specific diameter range \\
\hline RF & resolution factor \\
\hline$t_{c a l}$ & calculations time \\
\hline $\mathrm{V}_{\mathrm{s}}$ & superficial velocity $\left(\mathrm{m} \cdot \mathrm{s}^{-1}\right)$ \\
\hline $\mathrm{x}, \mathrm{y}, \mathrm{z}$ & nodes coordination $(\mathrm{m}, \mathrm{m}, \mathrm{m})$ \\
\hline
\end{tabular}

\section{Greek}

$\Delta \mathrm{P}$

$\varepsilon$

$\theta$

$\lambda$

$\mu$

$\rho$

$\sigma$

$\varphi_{\mathrm{s}}$

\section{Subscripts}

\section{$\mathrm{i}, \mathrm{j}, \mathrm{k}$}

c

g

$\mathrm{p}$

$\mathrm{s}$ pressure drop $\left(\mathrm{Kg} \cdot \mathrm{m}^{-1} \cdot \mathrm{s}^{-2}\right)$

porosity

volumetric water content $\left(\mathrm{m}^{3} \cdot \mathrm{m}^{-3}\right)$

scale parameters

dynamic viscosity $\left(\mathrm{Kg} \cdot \mathrm{m}^{-1} \cdot \mathrm{s}^{-1}\right)$

density $\left(\mathrm{Kg} \cdot \mathrm{m}^{-3}\right)$

variance of grain size distribution

sphericity factor

320 


\section{References}

325 Al-Dhahli, A.R.S., Geiger, S., van Dijke, M.I.J.: Three-Phase Pore-Network Modeling for

326 Reservoirs With Arbitrary Wettability. SPE J. 18, 285-295 (2013).

327 https://doi.org/10.2118/147991-PA

328 Anikeenko, A. V., Medvedev, N.N., Aste, T.: Structural and entropic insights into the nature 329 of the random-close-packing limit. Phys. Rev. E - Stat. Nonlinear, Soft Matter Phys. 77, 1-9 330 (2008). https://doi.org/10.1103/PhysRevE.77.031101

Arya, L.M., Paris, J.F.: A Physicoempirical Model to Predict the Soil Moisture Characteristic from Particle-Size Distribution and Bulk Density Data. Soil Sci. Soc. Am. J. 45, 1023-1030 (1981). https://doi.org/10.2136/sssaj1981.03615995004500060004x distributions in multicomponent sphere packs: application to the water retention curve. Colloids Surfaces A Physicochem. Eng. Asp. 127, 201-210 (1997). https://doi.org/https://doi.org/10.1016/S0927-7757(97)00144-1 hard spheres. Soft Matter. 10, 3826-3841 (2014). https://doi.org/10.1039/c3sm52959b Wilmers, J.: Generation of 3D representative volume elements for heterogeneous materials: A review, (2018) materials. Finite Elem. Anal. Des. 46, 165-180 (2010). https://doi.org/10.1016/j.finel.2009.06.030 
Braddock, R.D., Parlange, J.-Y., Lee, H.: Application of a Soil Water Hysteresis Model to

347 Simple Water Retention Curves. Transp. Porous Media. 44, 407-420 (2001).

348 https://doi.org/10.1023/A:1010792008870

Ch, N.K., Foteinopoulou, K., Laso, M.: Spontaneous crystallization in athermal polymer 350 packings. Int. J. Mol. Sci. 14, 332-358 (2013). https://doi.org/10.3390/ijms14010332 bimodal soil-water characteristic curve and hydraulic conductivity of compacted soils with different initial densities. Eng. Geol. 260, 105199 (2019). https://doi.org/https://doi.org/10.1016/j.enggeo.2019.105199 distribution on hydraulic permeability and eddy dispersion in bulk packings. Anal. Chem. 83, 3903-3910 (2011). https://doi.org/10.1021/ac200424p

Dorai, F., Rolland, M., Wachs, A., Marcoux, M., Climent, E.: Packing fixed bed reactors with cylinders: Influence of particle length distribution. Procedia Eng. 42, 1335-1345 (2012). https://doi.org/10.1016/j.proeng.2012.07.525 mathematical models describing particle size distribution of soils. Model. Earth Syst. Environ. 2, 166 (2016). https://doi.org/10.1007/s40808-016-0220-9

Farr, R.S., Groot, R.D.: Close packing density of polydisperse hard spheres. J. Chem. Phys. 131, (2009). https://doi.org/10.1063/1.3276799 soils using the soil-water characteristic curve. Can. Geotech. J. 31, 533-546 (1994) 
369

370

371

372

373

374

375

376

377

378

379

380

381

382

383

384

385

386

387

388

389

390

Phys. Rev. E - Stat. Physics, Plasmas, Fluids, Relat. Interdiscip. Top. 60, 7098-7104 (1999). https://doi.org/10.1103/PhysRevE.60.7098

Hitti, K., Bernacki, M.: Optimized Dropping and Rolling (ODR) method for packing of poly-disperse spheres. Appl. Math. Model. 37, 5715-5722 (2013).

https://doi.org/10.1016/j.apm.2012.11.018

Irani, C.F., Callis, R.R.: Particle size: measurement, interpretation and application (No. 531.36 I7). (1963)

Kansal, A.R., Torquato, S., Stillinger, F.H.: Computer generation of dense polydisperse sphere packings. J. Chem. Phys. 117, 8212-8218 (2002). https://doi.org/10.1063/1.1511510

Kyrylyuk, A. V., Wouterse, A., Philipse, A.P.: Random packings of rod-sphere mixtures simulated by mechanical contraction. AIP Conf. Proc. 1145, 211-214 (2009). https://doi.org/10.1063/1.3179895

Leong, E.-C.: Soil-water characteristic curves - Determination, estimation and application. Japanese Geotech. Soc. Spec. Publ. 7, 21-30 (2019). https://doi.org/10.3208/jgssp.v07.003

Li, S.X., Zhao, J., Lu, P., Xie, Y.: Maximum packing densities of basic 3D objects. Chinese Sci. Bull. 55, 114-119 (2010). https://doi.org/10.1007/s11434-009-0650-0

Loll, P., Moldrup, P., Schjønning, P., Riley, H.: Predicting saturated hydraulic conductivity from air permeability: Application in stochastic water infiltration modeling. Water Resour.

Res. 35, 2387-2400 (1999). https://doi.org/10.1029/1999WR900137

Rhodes, M.: Introduction to Particle Technology: Second Edition. John Wiley \& Sons (2008)

Santiso, E., Müller, E.A.: Dense packing of binary and polydisperse hard spheres. Mol. Phys. 100, 2461-2469 (2002). https://doi.org/10.1080/00268970210125313 
Shirazi, M.A., Boersma, L.: A Unifying Quantitative Analysis of Soil Texture. Soil Sci. Soc.

Tobochnik, J., Chapin, P.M.: Monte Carlo simulation of hard spheres near random closest packing using spherical boundary conditions. J. Chem. Phys. 88, 5824-5830 (1988). https://doi.org/10.1063/1.454542

Tong, F., Jing, L., Bin, T.: A Water Retention Curve Model for the Simulation of Coupled Thermo-Hydro-Mechanical Processes in Geological Porous Media. Transp. Porous Media. 91, 509-530 (2012). https://doi.org/10.1007/s11242-011-9857-z three dimensions. Nature. 239, 504-507 (1972). https://doi.org/10.1038/239504a0

Wen, T., Shao, L., Guo, X., Zhao, Y.: Experimental investigations of the soil water retention 402 curve under multiple drying-wetting cycles. Acta Geotech. 15, 3321-3326 (2020). https://doi.org/10.1007/s11440-020-00964-2 characteristics and their effects on the soil water characteristic curve. Eng. Geol. 284, 106035 (2021). https://doi.org/10.1016/j.enggeo.2021.106035 by mechanical contraction. Phys. Rev. E - Stat. Physics, Plasmas, Fluids, Relat. Interdiscip. Top. 67, 9 (2003). https://doi.org/10.1103/PhysRevE.67.051301

411 three-dimensional irregular packing problem. Appl. Math. Model. 41, 431-444 (2017).

412 https://doi.org/10.1016/j.apm.2016.09.018 
composites by Voronoi diagram in the Laguerre geometry based on random close packing of 415 spheres. Comput. Mater. Sci. 47, 951-961 (2010).

416 https://doi.org/10.1016/j.commatsci.2009.11.028

417 Xiong, Q., Baychev, T.G., Jivkov, A.P.: Review of pore network modelling of porous media:

418 Experimental characterisations, network constructions and applications to reactive transport.

419 J. Contam. Hydrol. 192, 101-117 (2016). https://doi.org/10.1016/j.jconhyd.2016.07.002

420 Zhai, Q., Rahardjo, H., Satyanaga, A., Dai, G.: Estimation of the soil-water characteristic

421 curve from the grain size distribution of coarse-grained soils. Eng. Geol. 267, 105502 (2020).

422 https://doi.org/https://doi.org/10.1016/j.enggeo.2020.105502

423 Zhou, J., Zhang, Y., Chen, J.K.: Numerical Simulation of Random Packing of Spherical

424 Particles for Powder-Based Additive Manufacturing. J. Manuf. Sci. Eng. 131, 031004 (2009).

425 https://doi.org/10.1115/1.3123324

426

427

428

429

TABLE captions:

430 Table 1. Algorithm used to generate porous media with arbitrary spheres.

431 Table 2. U.S. standard mesh sieve sizes and numbers.

432 Table 3. Mixing ratio for four sifted soil by their mass weight.

433 Table 4. Low and high values of the effective parameters for prediction the porosity (soil type $434 \quad 1)$

$435 \quad$ Figure captions: 
Figure 1. Discretization of continuum space and transformation to solvable matrix space in

MATLAB. (a) $R F=5$, (b) $R F=10$, (c) $R F=20$.

Figure 2. (a) Schematic of spheres allocation procedure and (b), (c) examination of overlap condition and probability matrix using Euclidean distance. (d) Generation and placing of spheres by suggested heuristic algorithm.

Figure 3. Sifted soil grains with different grading. (a):2-3.35 mm, (b):1.18-2mm, (c):0.6$1.18 \mathrm{~mm},(\mathrm{~d}): 0.3-0.6 \mathrm{~mm}$

Figure 4. Prepared soil samples for porosity measurement.

Figure 5. Hydraulic conductivity and pressure drop measurement setup based on ASTM D 2434-68, (a) schematic of the pilot, (b) Soil column with inlet and outlet and 4 manometers, (c) Uniform distributor at column entrance and sealing gel (D) Light-duty flat strap designed to increase or decrease water head, (e) Glass marbles used to prevent flow turbulence

Figure 6. (a) Simulated Porous media structure for soil type one, (b) top and (c) bottom view.

Figure 7. (a) Simulated structure of the granular porous media for particle size distribution of 25 microns to 3350 microns, (b) top and (c) bottom view.

Figure 8. Comparison of predicted and measured porosity values.

Figure 9. Sensitivity analysis results for prediction of porosity (soil type 1).

Figure 10. Comparison of estimated and measured pressure drop; (a) soil type 1 and (b) soil 454 type 2.

455 Figure 11. Equal pressure drop along soil column in monometers.

456 Figure 12. Comparison of predicted and measured saturated hydraulic conductivity (soil type $457 \quad 1$ and 2). 


\begin{tabular}{|c|c|}
\hline \multicolumn{2}{|c|}{ Algorithm: } \\
\hline 1 & Inputs: the set of radius $\left\{r_{i}\right\}$, the desired density $(1-\varepsilon)$ \\
\hline 2 & Calculate the cube size $l$ to achieve density $(1-\varepsilon)$ \\
\hline 3 & $\begin{array}{l}\text { Create the grid network }\left[g_{x}, g_{y}, g_{z}\right] \mathrm{c} \text { along three } \\
\text { dimension based on resolution parameter } R F\end{array}$ \\
\hline 4 & Place the first sphere in the $p_{l}=\left[\mathrm{r}_{1} / 2, \mathrm{r}_{1} / 2, \mathrm{r}_{1} / 2\right]$ \\
\hline 5 & Set $\mathrm{z}=\mathrm{Z}_{\min }$ and $P_{t}=\left\{p_{1}\right\}, i=2$ \\
\hline 6 & Remove the grid points that would be in a first sphere \\
\hline 7 & While $i<=$ Number of spheres \\
\hline 8 & $\begin{array}{l}\text { Calculate the average center } C_{\text {avg }} \text { equal to } \\
\text { mean of } P_{t} \text { in each dimension. }\end{array}$ \\
\hline 9 & $r_{\text {next }}=r_{i ;}$ \\
\hline 10 & $\begin{array}{l}\text { Calculate the Euclidean distance between all } \\
\text { grid networks from } C_{\text {avg }} \text { and keep them in } \\
\text { distance avg. }\end{array}$ \\
\hline 11 & $\begin{array}{l}\text { Set the distance_avg of grid points that leads } \\
\text { to collision of dedicated spheres to be a large } \\
\text { number. }\end{array}$ \\
\hline 12 & $\begin{array}{l}\text { Find the minimum value of distance_avg and } \\
\text { place the next sphere's center in this grid } \\
\text { point } p_{i} \text {. }\end{array}$ \\
\hline 13 & Add the $p_{i}$ to $P_{t}$ \\
\hline 14 & $\begin{array}{l}\text { Remove the grid points that would be in this } \\
\text { sphere. }\end{array}$ \\
\hline 15 & $i=i+1$ \\
\hline 16 & End While. \\
\hline 17 & Output: the $P_{t}$ determines the place of all the spheres. \\
\hline
\end{tabular}




\begin{tabular}{|c|c|c|c|c|c|}
\hline Mesh Number $^{*}$ & 6 & 10 & 16 & 30 & 50 \\
\hline Standard mesh size (mm) $^{(m)}$ & 3.35 & 2 & 1.18 & 0.6 & 0.3 \\
\hline
\end{tabular}

* The standard sieve number indicates the number of holes per square inch of sieve

Table 3. Mixing ratio for four soils by their mass weight

\begin{tabular}{|c|c|c|c|c|}
\hline & ${ }^{*}$ Type 1 & Type 2 & Type 3 & Type 4 \\
\hline $0.3-0.6 \mathrm{~mm}$ & 3 & 2 & 1 & 1 \\
\hline $0.6-1.18 \mathrm{~mm}$ & 3 & 2 & 1 & 1 \\
\hline $1.18-2 \mathrm{~mm}$ & 1 & 2 & 2 & 3 \\
\hline $2-3.35 \mathrm{~mm}$ & 1 & 1 & 2 & 3 \\
\hline * Type points out the assumed mixing ratios. For example, each $6 \mathrm{~kg}$ prepared \\
soil type 1 consists of 3, 3, 1, and 1 kg of soil particles in the range of 0.3-0.6 \\
mm, 0.6-1.18 mm, 1.18-2 mm, and 2-3.35 mm, respectively.
\end{tabular}

473

474

475 Table 4. Low and high values of the effective parameters for prediction the porosity (soil type 1)

\begin{tabular}{|c|c|c|c|c|c|}
\hline & low value & high value & most likely & $\begin{array}{c}\text { pessimistic } \\
\text { porosity (\%) }\end{array}$ & $\begin{array}{c}\text { optimistic } \\
\text { porosity (\%) }\end{array}$ \\
\hline Parameters & & & & & \\
\hline Resolution Factor & 50 & 300 & 150 & 47.41 & 43.89 \\
\hline Distribution Function & Normal & Weibull & Weibull & 41.33 & 44.37 \\
\hline Replication & 1 & 10 & 3 & 44.92 & 44.52 \\
\hline \multicolumn{7}{|r|}{} & & & & \\
\hline Measured Porosity & $43.26 \%$ & & & & \\
\hline
\end{tabular}



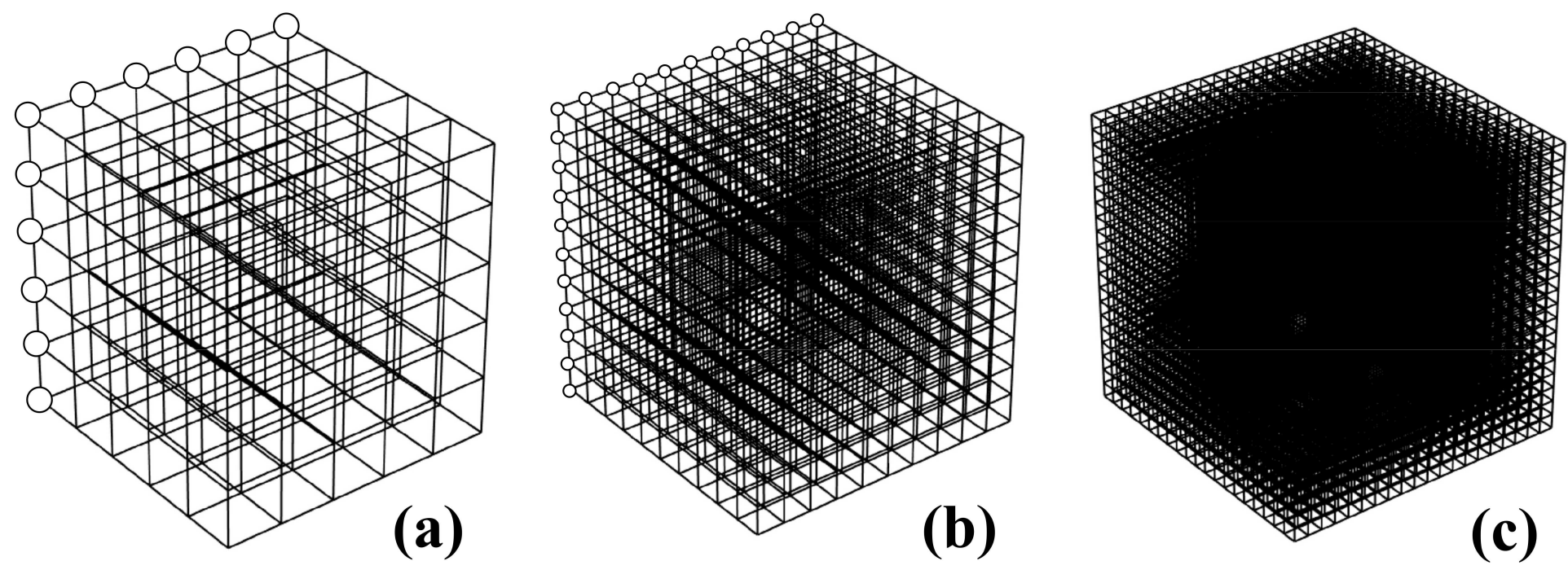

Figure 1

Discretization of continuum space and transformation to solvable matrix space in MATLAB. (a) $R F=5$, (b) $\mathrm{RF}=10$, (c) $\mathrm{RF}=20$. 
(a)

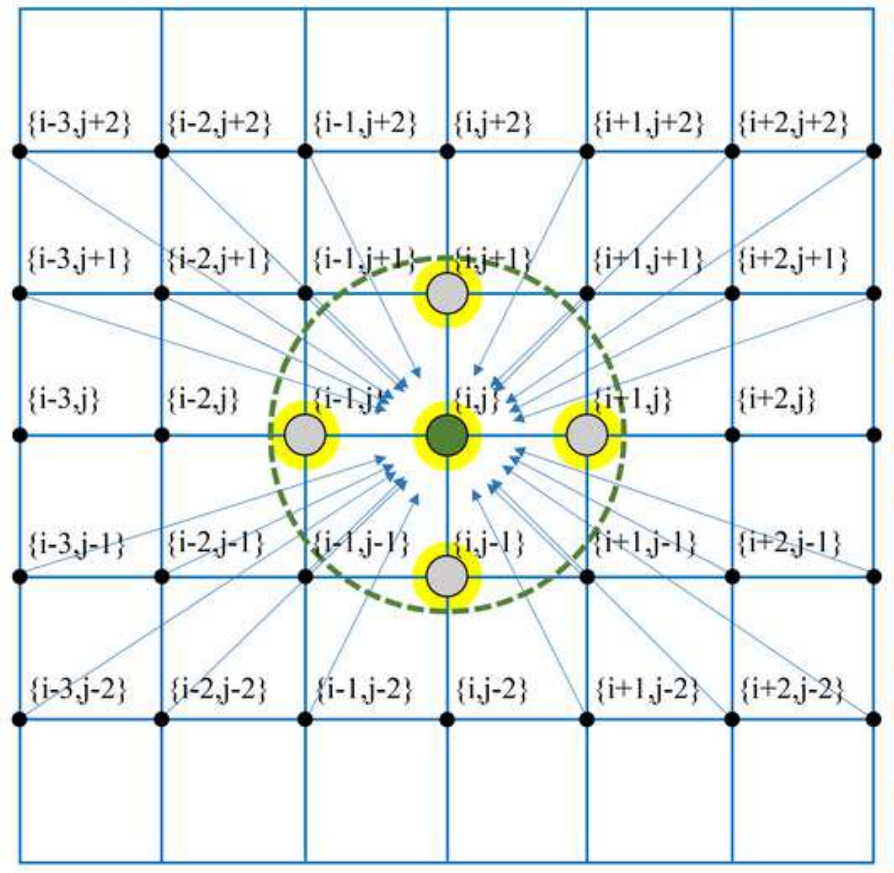

(c)

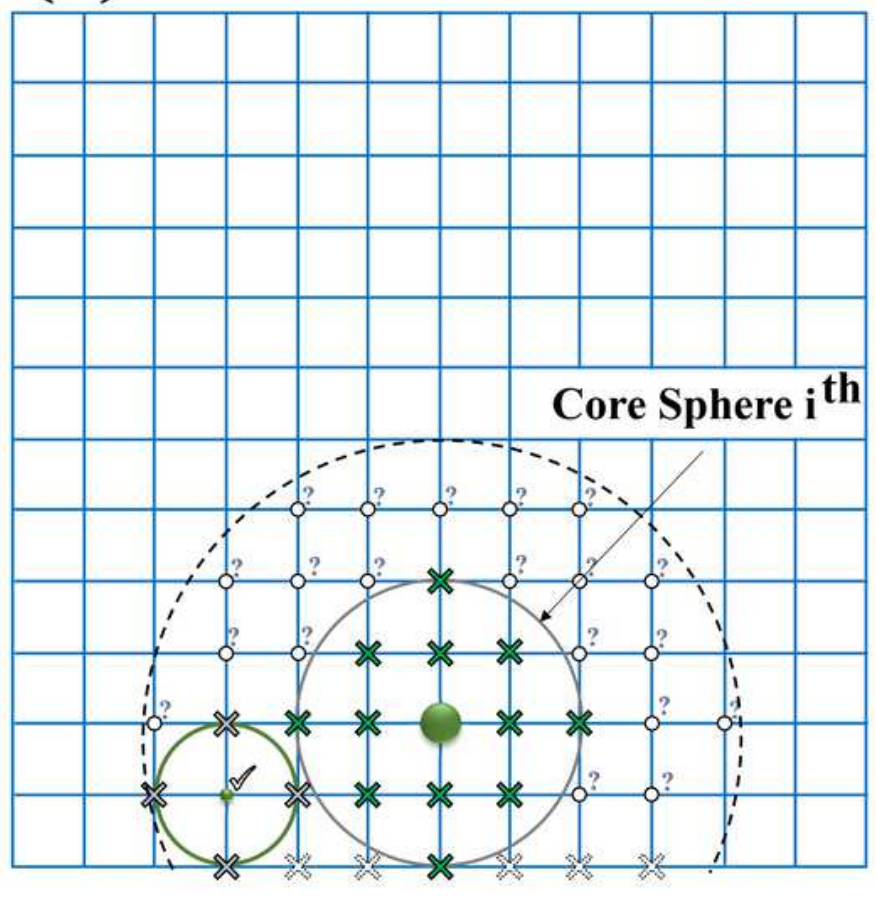

(b)

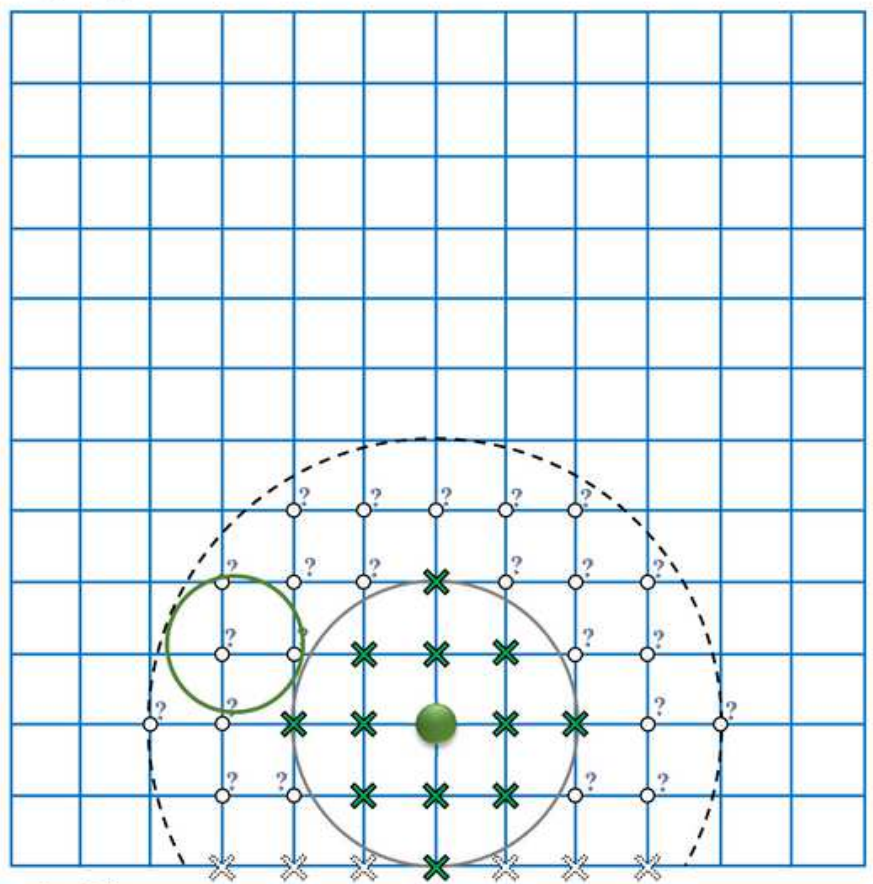

(d)
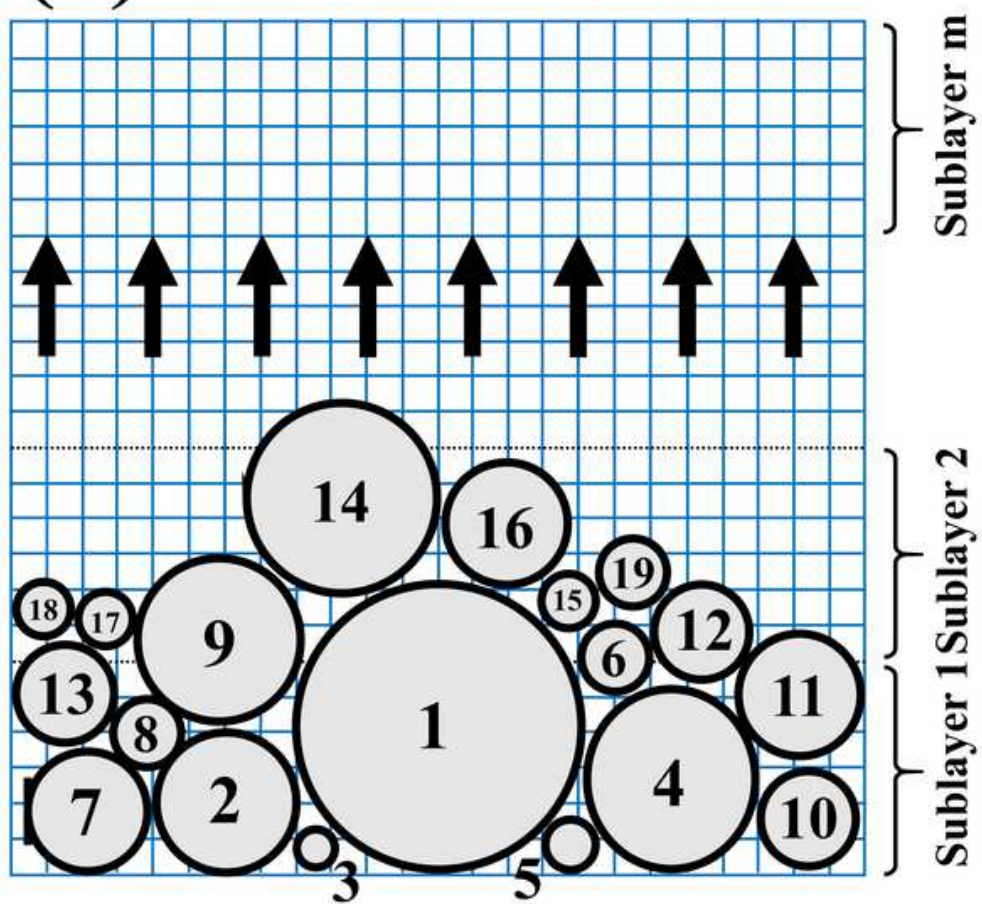

Figure 2

(a) Schematic of spheres allocation procedure and (b), (c) examination of overlap condition and probability matrix using Euclidean distance. (d) Generation and placing of spheres by suggested heuristic algorithm. 

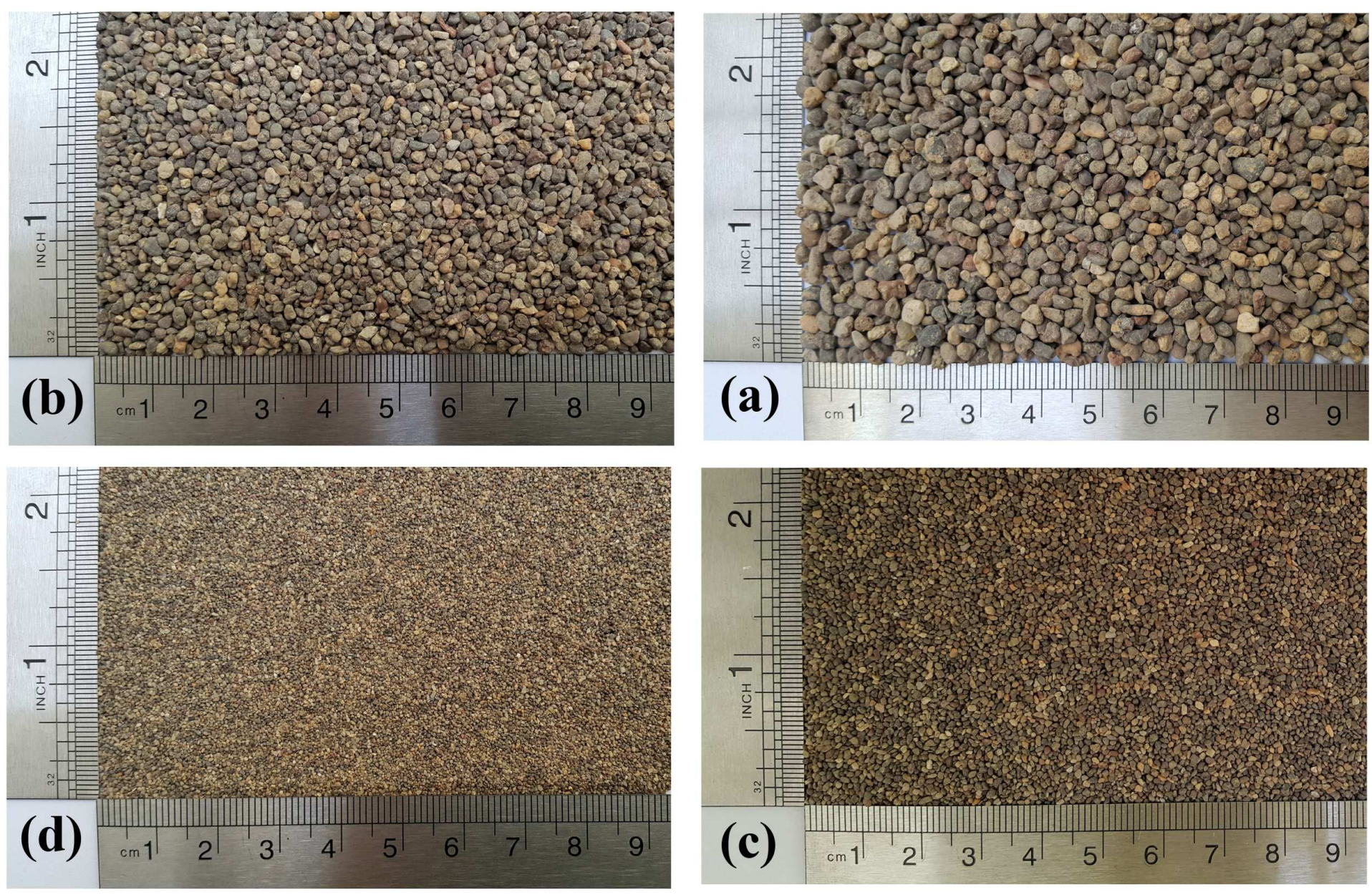

\section{Figure 3}

Sifted soil grains with different grading. (a):2-3.35 mm, (b):1.18-2mm, (c):0.6-1.18mm, (d):0.3-0.6mm 


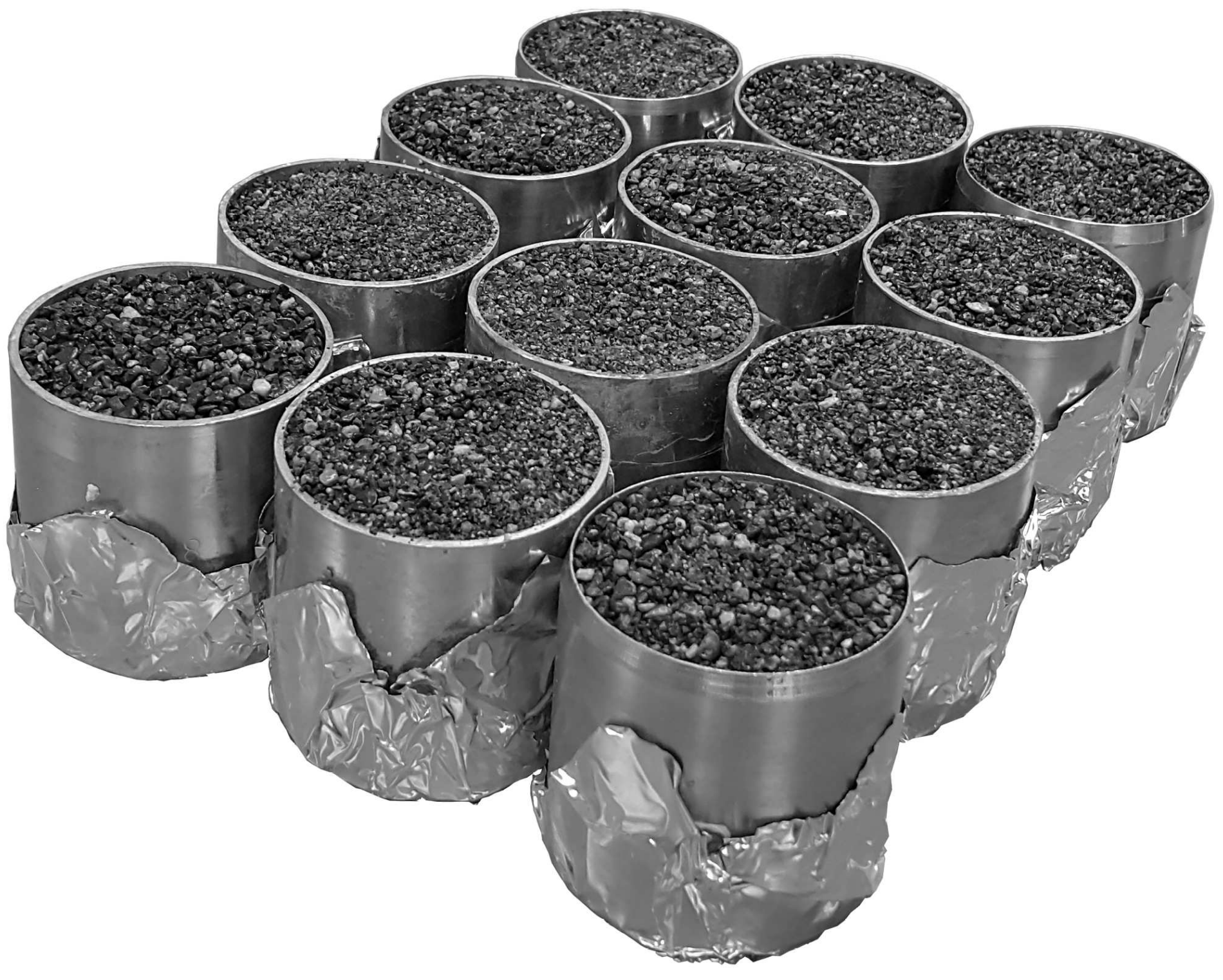

Figure 4

Prepared soil samples for porosity measurement. 


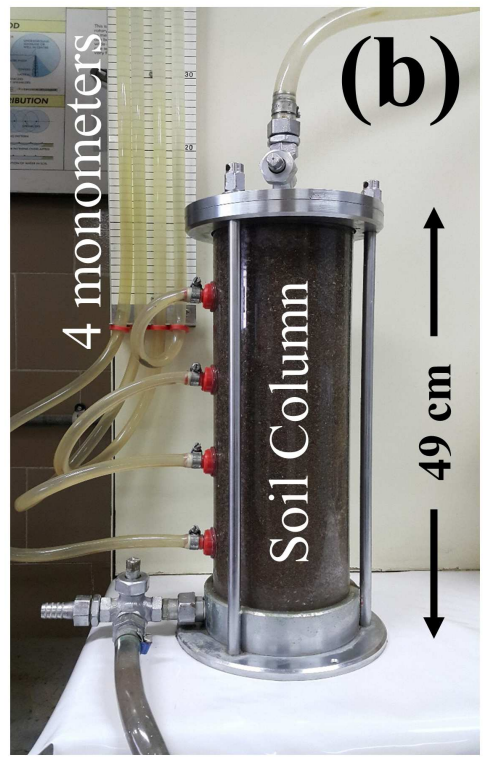

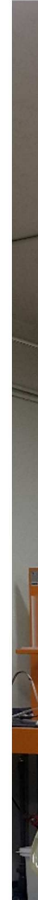
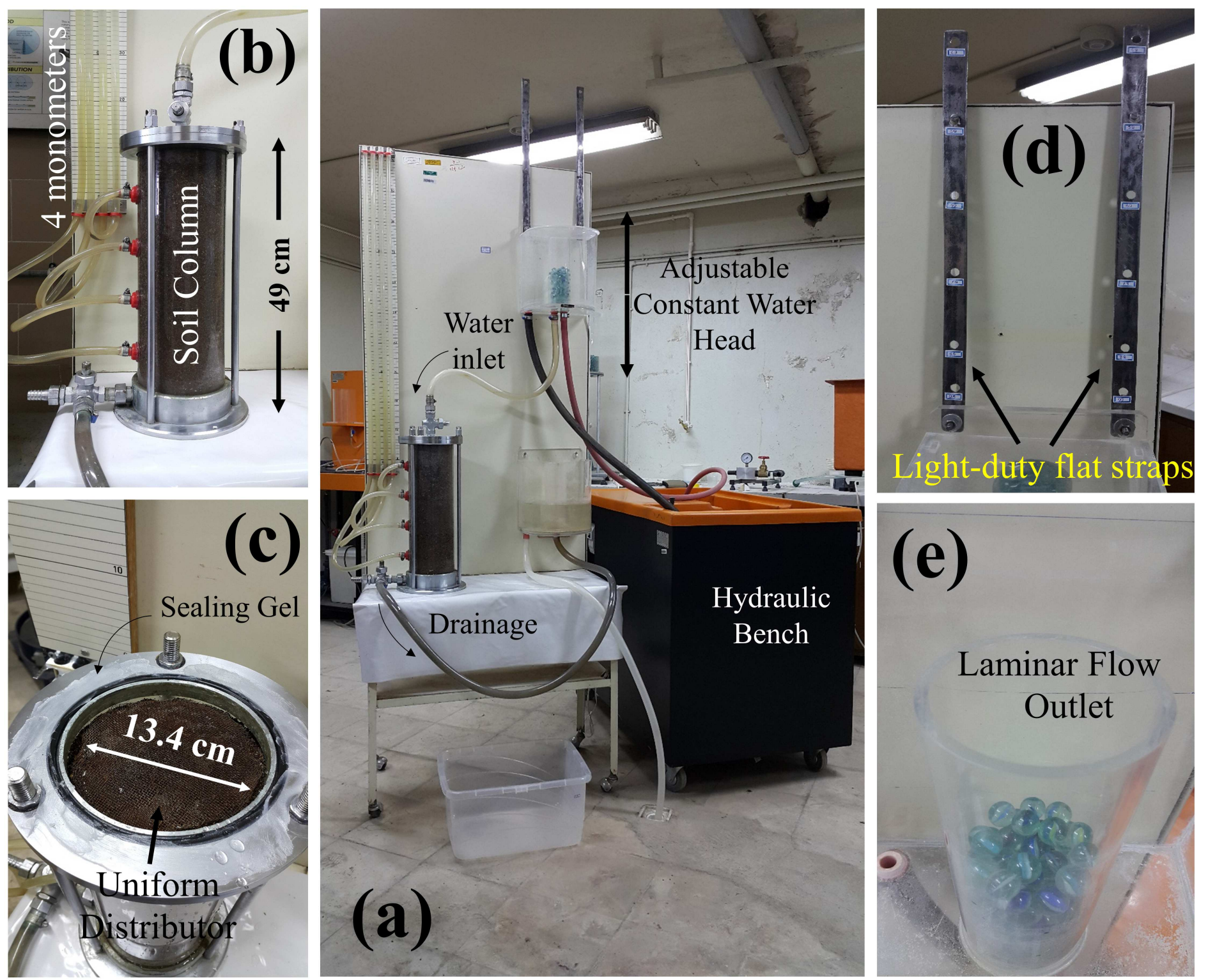

\section{Figure 5}

Hydraulic conductivity and pressure drop measurement setup based on ASTM D 2434-68, (a) schematic of the pilot, (b) Soil column with inlet and outlet and 4 manometers, (c) Uniform distributor at column entrance and sealing gel (D) Light-duty flat strap designed to increase or decrease water head, (e) Glass marbles used to prevent flow turbulence 

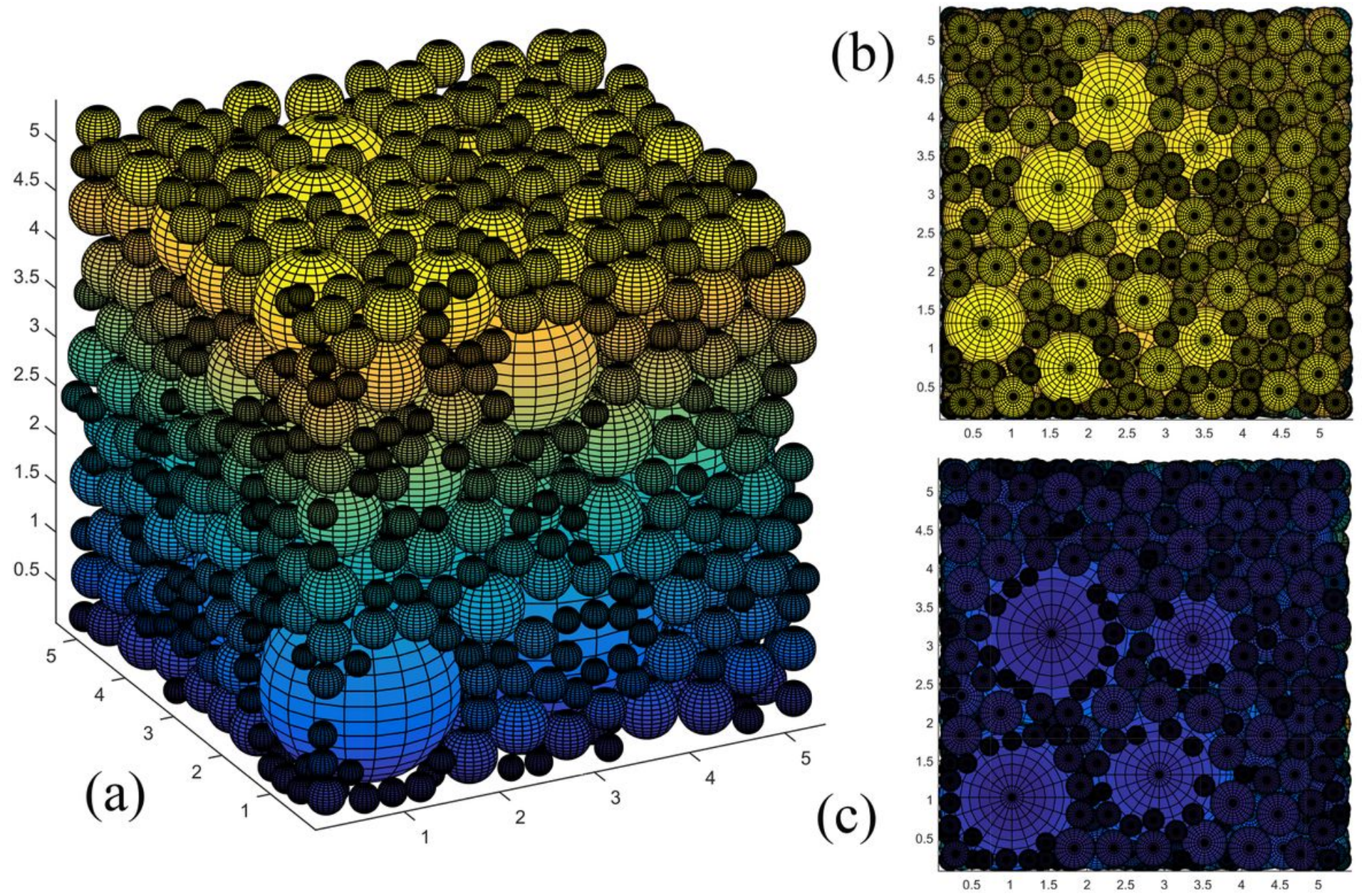

Figure 6

(a) Simulated Porous media structure for soil type one, (b) top and (c) bottom view. 

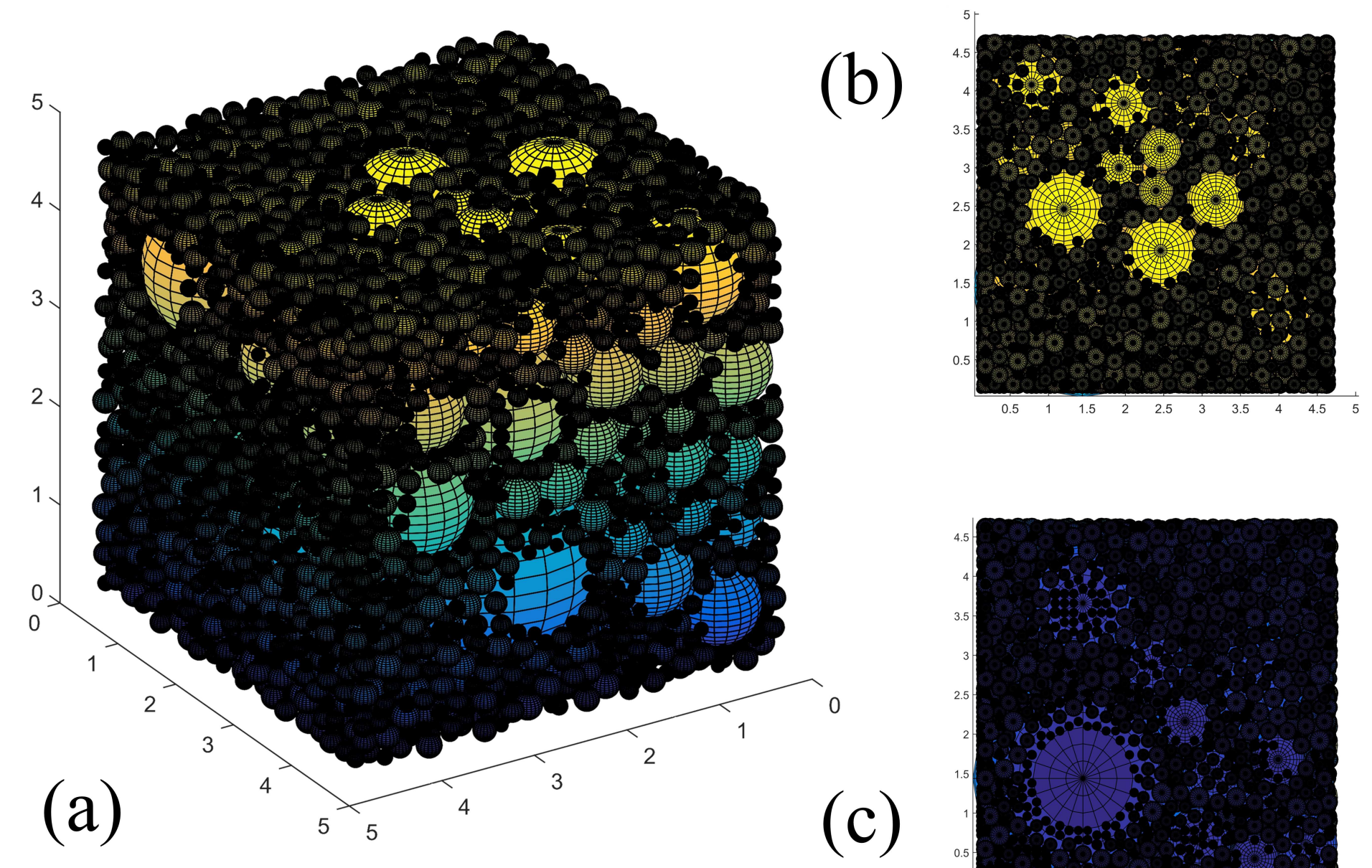

Figure 7

(a) Simulated structure of the granular porous media for particle size distribution of 25 microns to 3350 microns, (b) top and (c) bottom view. 


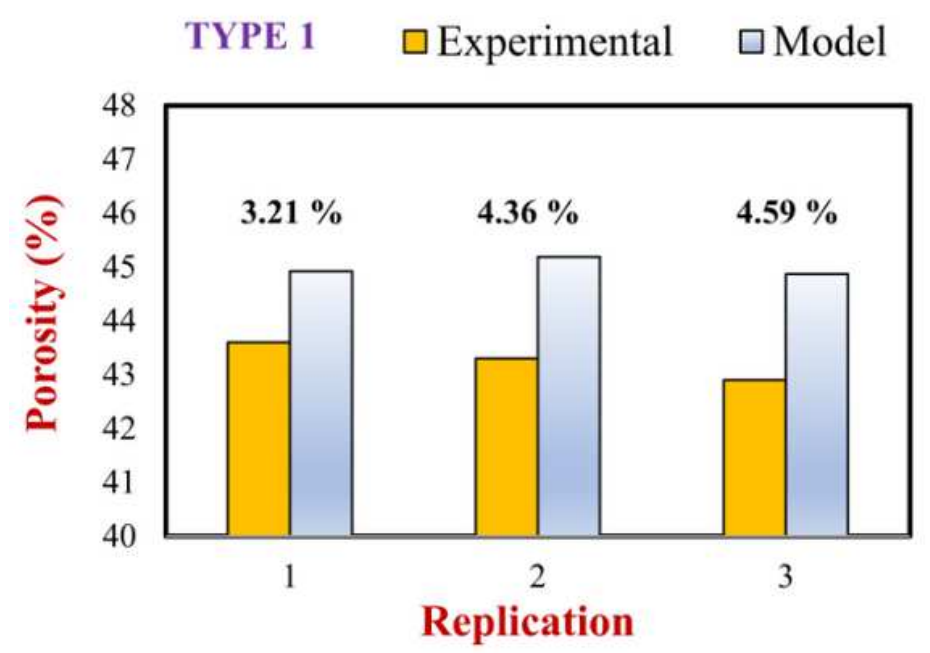

TYPE $2 \square$ Experimental $\square$ Model

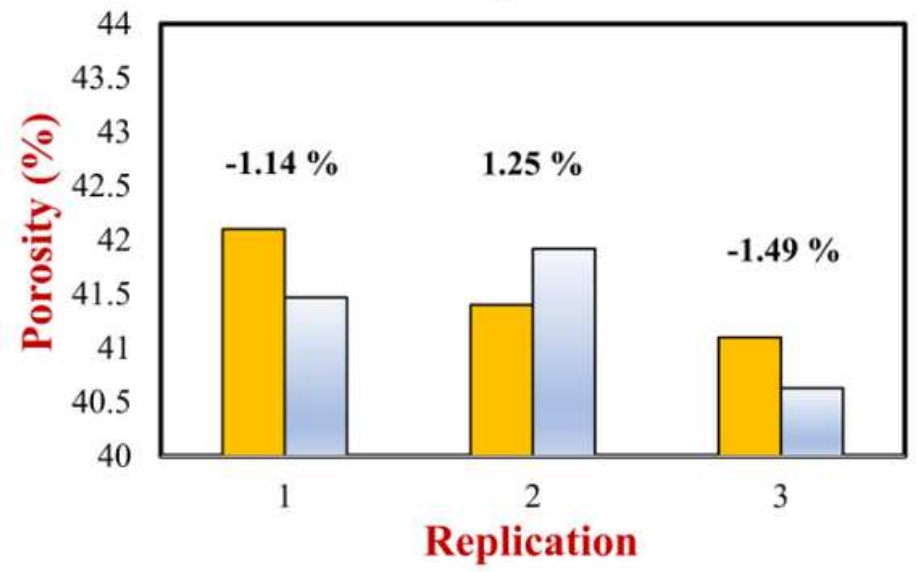

TYPE $3 \quad \square$ Experimental $\square$ Model

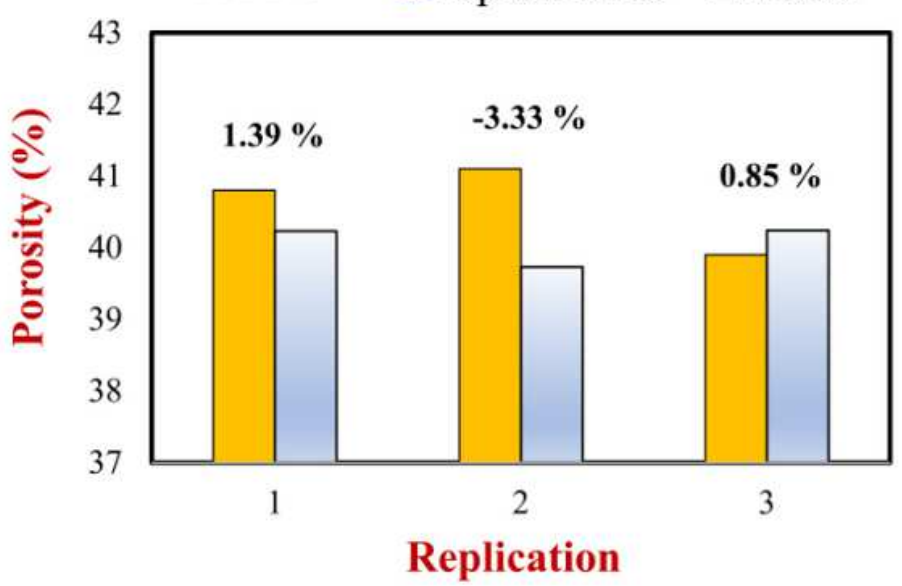

TYPE $4 \quad \square$ Experimental $\square$ Model

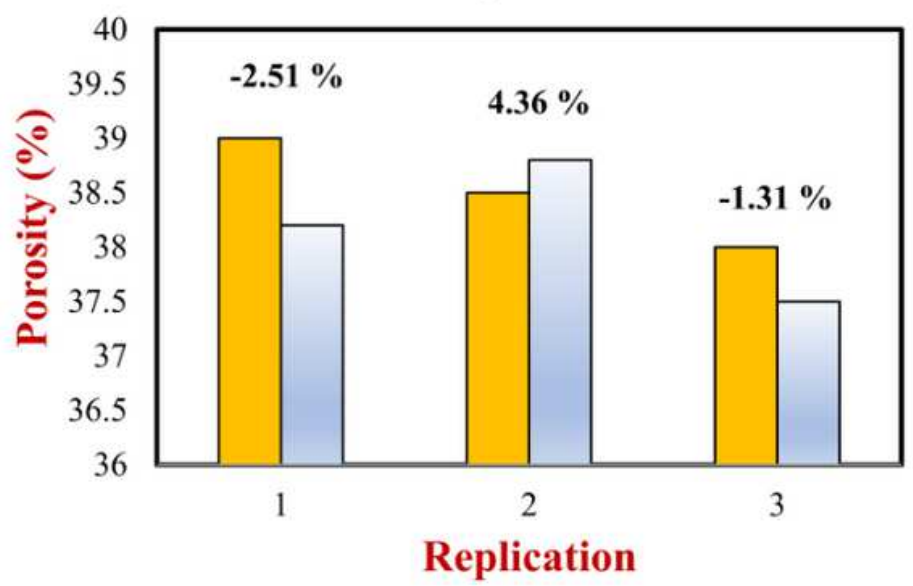

Figure 8

Comparison of predicted and measured porosity values. 
- Optimistic

口Pessimistic

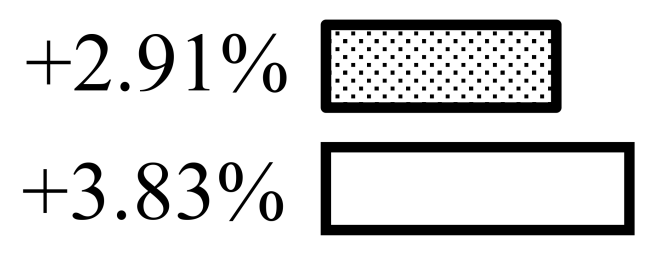

$+2.56 \%$ $-4.46 \%$
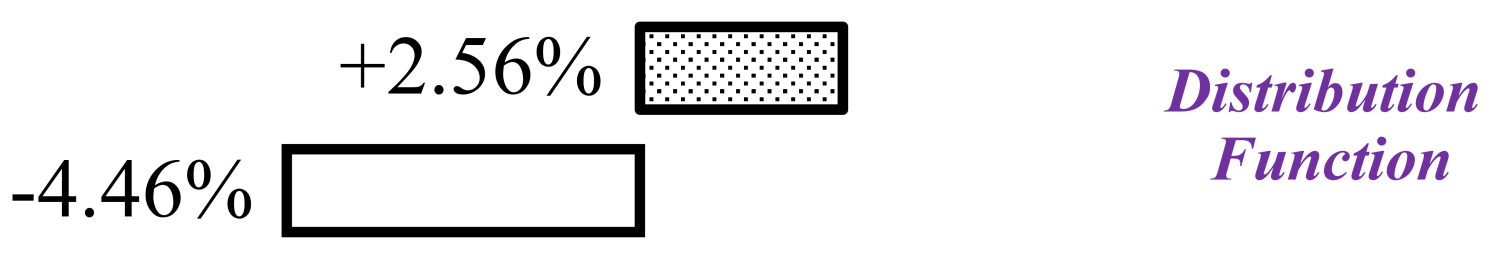

Distribution Function

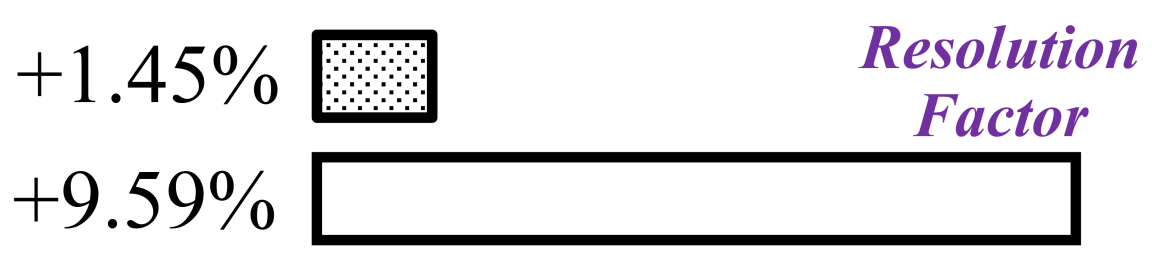

38

40

42

44

46

Figure 9

Sensitivity analysis results for prediction of porosity (soil type 1). 

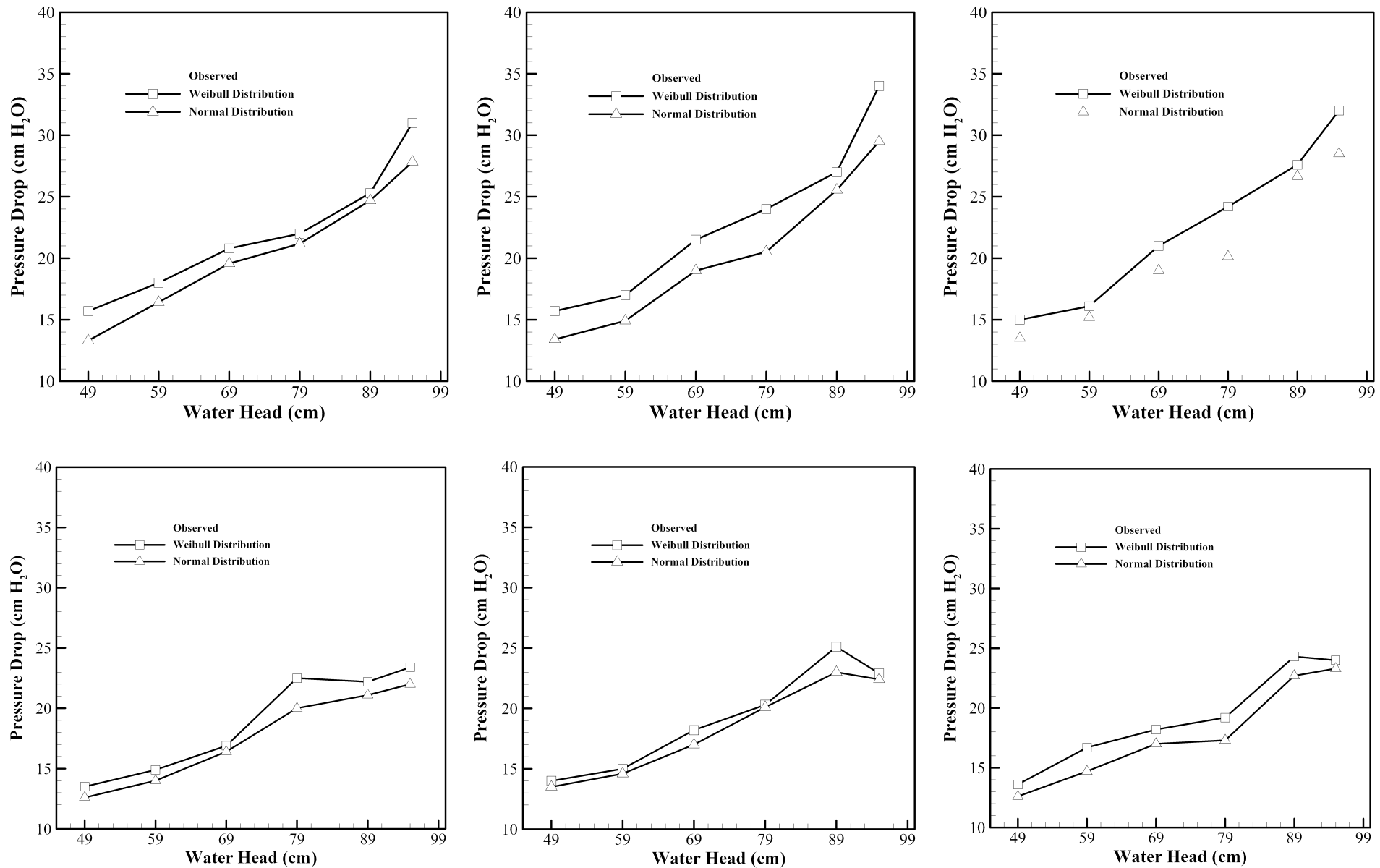

Figure 10

Comparison of estimated and measured pressure drop; (a) soil type 1 and (b) soil type 2 . 

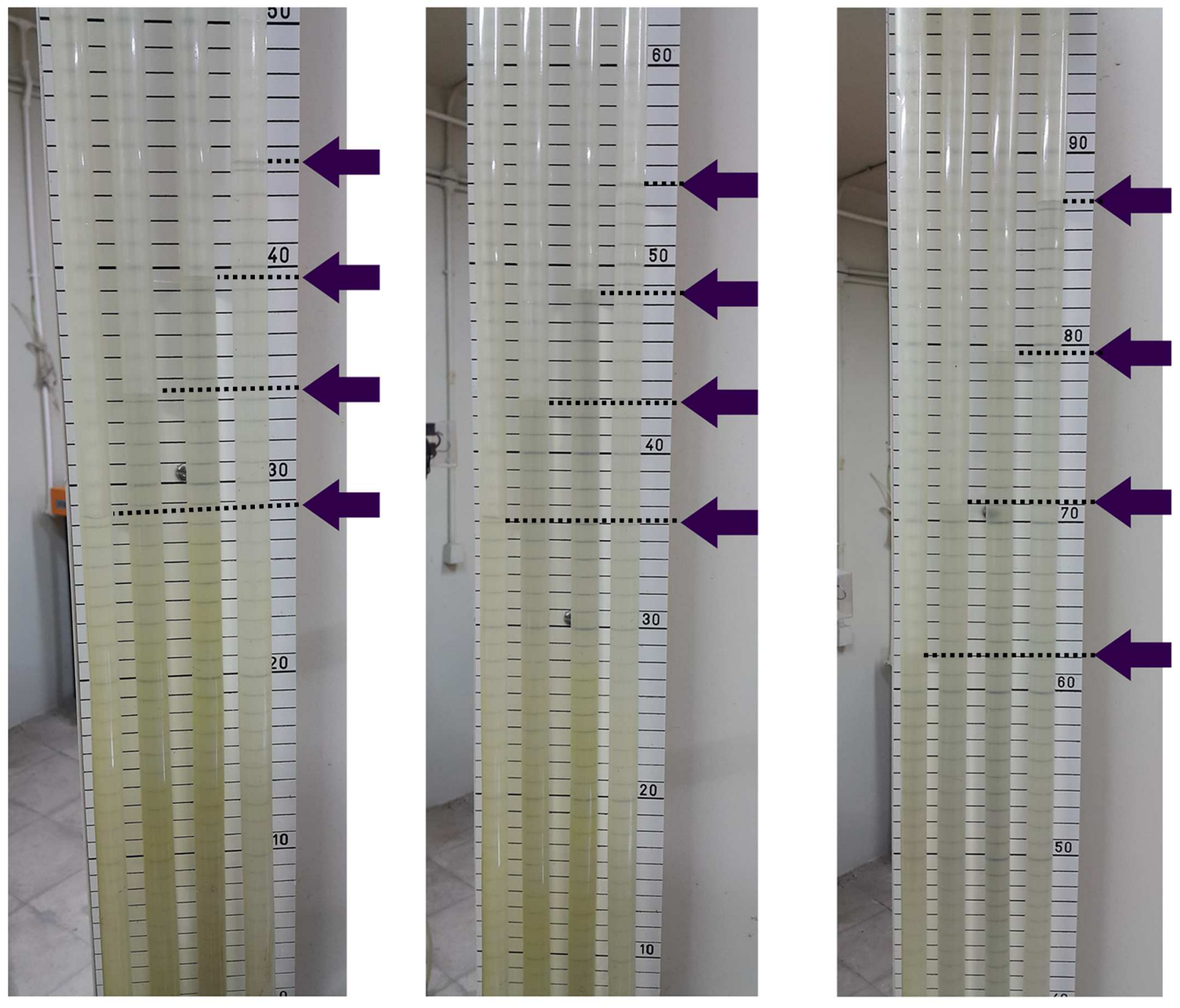

Figure 11

Equal pressure drop along soil column in monometers. 

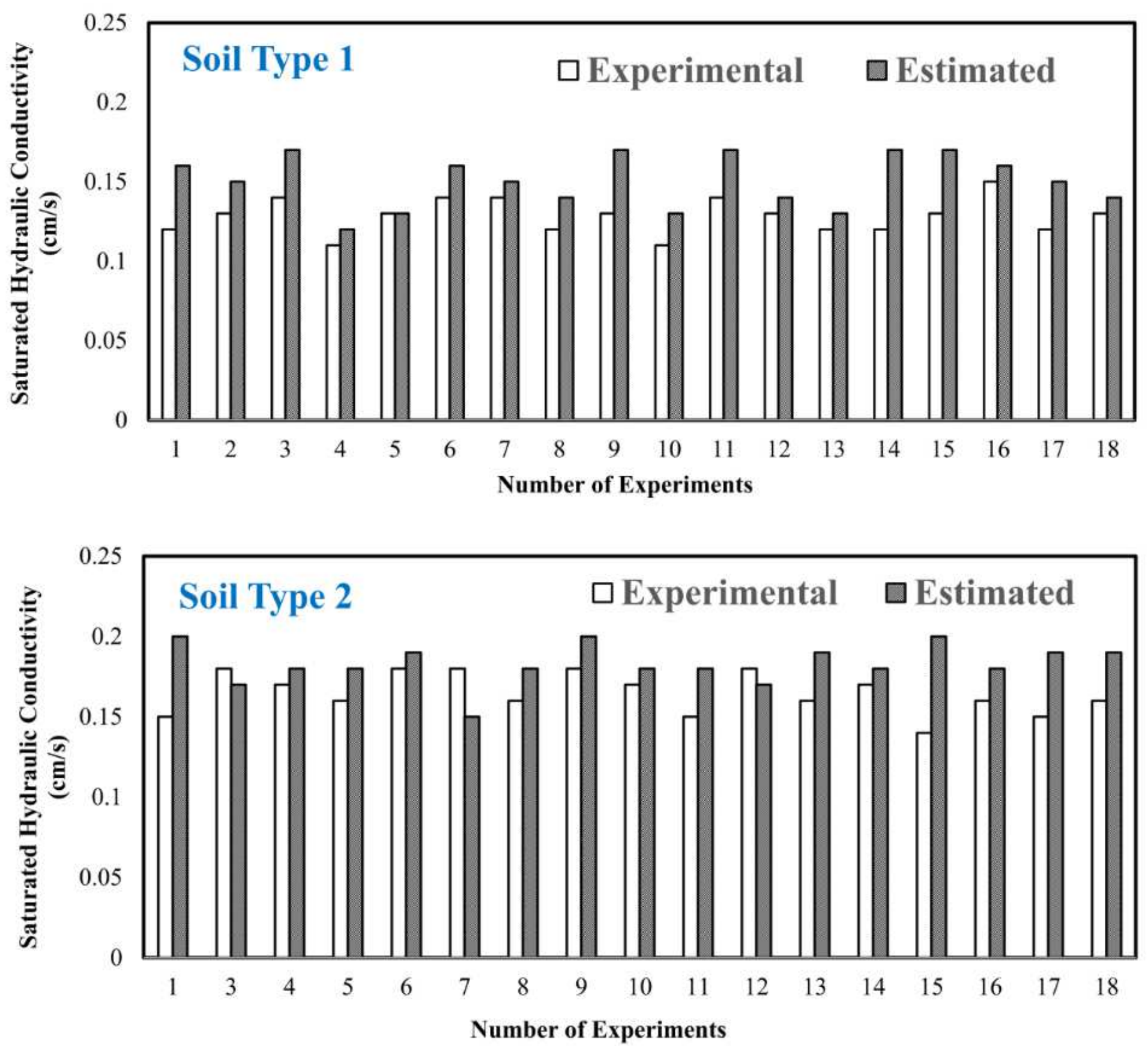

Figure 12

Comparison of predicted and measured saturated hydraulic conductivity (soil type 1 and 2). 

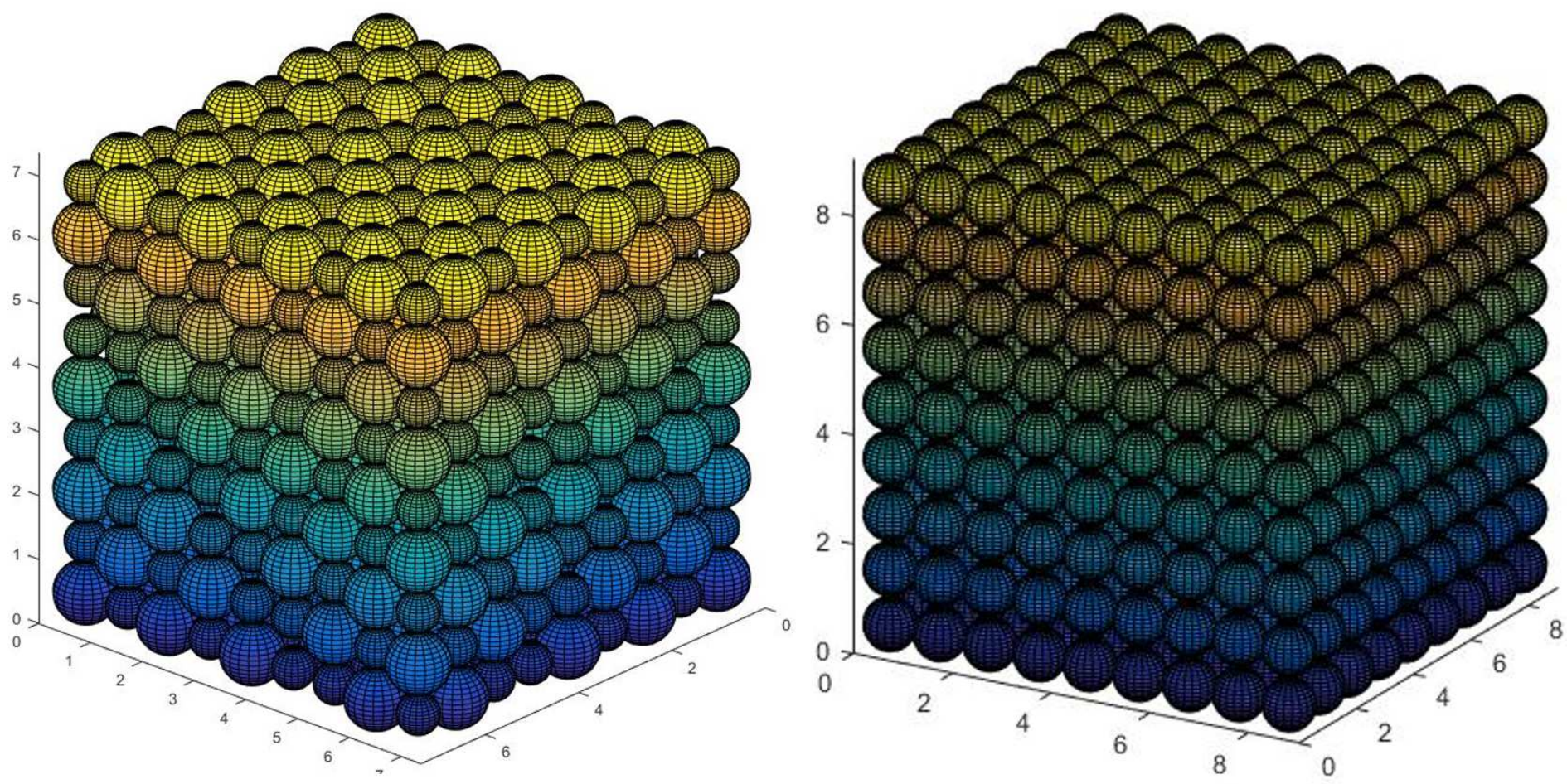

Figure 13

Structured random close packing generated by presented algorithm.

\section{Supplementary Files}

This is a list of supplementary files associated with this preprint. Click to download.

- GraphicalAbstract.tif 